\title{
A controlled study of stanozolol in primary Raynaud's phenomenon and systemic sclerosis
}

\author{
Malcolm I V Jayson, Christopher D Holland, Anita Keegan, Karen Illingworth, \\ Lesley Taylor
}

\begin{abstract}
A double blind, crossover study of fibrinolytic enhancement treatment using stanozolol has been performed in primary Raynaud's phenomenon and in systemic sclerosis. The outcome criteria included subjective evaluation, clinical examination, physiological measurements of peripheral blood flow, and fibrinolytic measurements. Nineteen patients entered and 11 completed the study of primary Raynaud's phenomenon. There was nonsignificant evidence of improvement in peripheral blood flow. Twenty four patients entered and 17 completed the study of systemic sclerosis. There was marked objective but not subjective evidence of improvement in the peripheral microcirculation during the stanozolol treatment period. There was also a nonsignificant improvement in dermal sclerosis. There were improvements in fibrinolytic activity during the stanozolol treatment period. There was no alteration in fibrinolytic reserve as measured by 1-desamino-8-D-arginine vasopressin stimulation, however. Although adverse events were common in both treatment periods, withdrawals predominantly occurred during the period of treatment with stanozolol and were principally due to anabolic problems. There does not seem to be any indication for the use of stanozolol in primary Raynaud's phenomenon. Fibrinolytic enhancement with stanozolol does appear useful in treating the microvascular features of systemic sclerosis.
\end{abstract}

Raynaud's phenomenon is a syndrome in which exposure to cold and often other stimuli produces transient digital ischaemia with a biphasic or triphasic colour change commonly associated with numbness and paraesthesiae. In primary Raynaud's phenomenon no underlying cause can be found, whereas in secondary Raynaud's phenomenon, connective tissue diseases and, in particular, systemic sclerosis are important causes. Systemic sclerosis is characterised by progressive vascular obstruction, excessive proliferation of connective tissue elements, and, especially, collagen and ischaemic atrophy of the tissues. Patients commonly have severe Raynaud's phenomenon, often complicated by digital pitting and ulceration. The characteristic vascular disease includes arteriolar intimal proliferation with fibrin deposition associated with endothelial damage and platelet aggregation and adherence. These changes lead to progressive vascular obstruction. In addition, there is hyperfibrinogenaemia with hyper- viscosity of the blood, ${ }^{1}$ particularly at low temperatures and at low shear rates ${ }^{2}$ as occurs in peripheral vessels in the hands with defective fibrinolytic activity. ${ }^{3}$ For this reason stimulation of the fibrinolytic system and correction of this fibrinolytic defect may be of therapeutic value in correcting the vascular problems by improving vascular patency and reducing plasma viscosity. ${ }^{4}$ We therefore conducted a double blind, controlled trial of stimulating the fibrinolytic system with stanozolol, which is an anabolic steroid with low virilising potential and is known to enhance and normalise impaired fibrinolytic activity.

\section{Patients and methods}

PATIENTS

Nineteen patients with primary Raynaud's phenomenon (17 women, two men; mean age 43.3 (SE 3.3) years; mean duration of disease $109 \cdot 3$ (SE 27.8) months) and 24 patients with systemic sclerosis ( 22 women, two men; mean age $50.5(2.8)$ years; mean duration of disease 206.0 (32.7) months) entered the study. Patients were not taking drugs which might influence fibrinolytic activity, and had no evidence of cardiac, hepatic, renal or other disease known to influence fibrinolysis or which might contraindicate the use of stanozolol. Women patients, additionally, were not pregnant, had no risk of pregnancy, or were using effective contraceptive methods, excluding the pill. There were seven current smokers in the group with primary Raynaud's phenomenon and seven in the group with systemic sclerosis. All gave written informed consent and the study was performed with the approval of the Salford ethical committee.

Patients with primary Raynaud's phenomenon had bilateral symmetrical Raynaud's phenomenon, with at least two of the three colour changes in response to cold, with no evidence of mechanical or drug induced causes of Raynaud's phenomenon, and no clinical or laboratory evidence of connective tissue disorders, including negative tests for antinuclear factor, extractable nuclear antigen, and anticentromere antibody.

Patients with systemic sclerosis satisfied the American Rheumatism Association criteria ${ }^{5}$ for definite systemic sclerosis and also had Raynaud's phenomenon.

\section{TREATMENT}

Treatment was with either stanozolol $5 \mathrm{mg}$ orally twice a day or matching placebo tablets 
twice a day. Patients were randomly allocated to receive six months treatment with stanozolol or placebo given in a double blind fashion and then crossed over to the alternate regimen for a further period of six months.

\section{ASSESSMENTS}

Assessments were performed one week before entry, on entry to the study, and at four, 12, and 24 weeks of the first treatment period, and again at four, 12, and 24 weeks of the second treatment period.

Adverse events were assessed by a standard questionnaire covering all possible problems before entry to the trial and at each assessment. A blood count, renal and liver function tests, and urine examination were undertaken at each assessment.

On entry patients underwent detailed assessments of the severity and duration of disease. To assess progress sequential measurements of clinical and physiological variables and fibrinolytic changes were made.

\section{Clinical variables}

A subjective assessment was obtained by noting the frequency and duration of Raynaud's phenomenon using diary cards.

For patients with systemic sclerosis a measurement of skin disease was made with a modified Rodnan scleroderma skin score, grip strengths in both hands, the ability to make a fist measured by the sum of the distances between the finger tips and the transverse palm crease, the intervermilion distance on opening the mouth, and the degrees of fixed flexion of the elbows.

\section{Physiological variables}

Patients attended at the same time each morning having fasted from the previous midnight. After resting for 30 minutes in a room with controlled temperature $\left(20 \pm 0.5^{\circ} \mathrm{C}\right)$ and humidity $(45 \pm 5 \%)$ the following measurements of the peripheral circulation were made: (1) Ultrasonic Doppler index of digital artery patency, in which the patencies of digital artery segments are recorded by auscultation for arterial flow over the medial and lateral sides of each phalanx. There are six segments for each finger and four for each thumb so that the maximum total for the two hands is 56. (2) The skin temperature over the finger pulps and nail beds using a Heimann medical infrared thermometer.

\section{Fibrinolytic measurements}

A $10 \mathrm{ml}$ venous blood sample was taken without a tourniquet by a 'clean' single venepuncture technique. The following fibrinolytic measurements were performed: euglobulin clot lysis time (ELT) in an automated clot lysis recorder; fibrin plate lysis area (FPLA); fibrinogen, plasminogen, $\boldsymbol{\alpha}_{2}$ macroglobulin, $\boldsymbol{\alpha}_{2}$ antiplasmin. The maximum plasminogen activator reserve was measured after taking the $10 \mathrm{ml}$ basal blood sample by inserting a butterfly intravenous cannula into a suitable arm vein and infusing $10 \mu \mathrm{g}$ of 1-desamino-8-D-arginine vasopressin (DDAVP) diluted in $25 \mathrm{ml}$ sterile saline over 15 minutes. A further $5 \mathrm{ml}$ of blood was then taken by repeat 'clean' venepuncture for ELT and FPLA measurements.

\section{STATISTICAL TECHNIQUES}

The data were analysed to determine whether there were any carry over effects for the incidence and duration of Raynaud's attacks and the reporting of adverse events between the stanozolol and placebo periods of treatment. ${ }^{6}$ No significant effects were detected. The subsequent analyses combined the data from both treatment periods.

The changes occurring within each treatment period and the differences between the effects of the stanozolol and placebo treatment periods were tested with Student's $t$ test.

\section{Results}

SUBJECTS STUDIED AND ADVERSE EVENTS

Of the 21 patients with primary Raynaud's phenomenon, 11 completed the study receiving both stanozolol and placebo for a period of six months each. Two patients were excluded (one through lack of interest, one was too young). Seven patients withdrew during the stanozolol treatment period and one while being treated with placebo. Despite the precautions listed in the entry criteria two had become pregnant, one while receiving stanozolol and the other during the placebo period. The trial drug was stopped at 12 and seven weeks of pregnancy respectively; spontaneous abortions occurred a further five and three weeks later. Of the 24 patients with systemic sclerosis, 17 completed the study and seven withdrew, six while receiving stanozolol and one during the placebo period.

An attempt was made to analyse the effects of the weather on the study. This proved extremely difficult. Study of the data, however, showed that the assessments were similarly distributed in the warmer and cooler halves of the year for both stanozolol and placebo treatment periods.

Table 1 shows the reasons for withdrawal. Weight gain and muscle cramps were the most common problems during treatment with stanozolol. Adverse events not requiring withdrawal from the study were in general more common during the stanozolol period than the placebo periods (primary Raynaud's phenomenon study 145 events during stanozolol and 121 during placebo treatment; systemic sclerosis study 210 during stanozolol and 156 during placebo treatment), but the differences were not statistically significant.

One patient died during the trial. She was a 73 year old patient with a four year history of rapidly progressive systemic sclerosis. She had severe diffuse cutaneous features of the disease and also gastrointestinal tract disease. She had been receiving stanozolol for five months and was admitted to hospital with acute liver damage and acute renal failure. Two months previously her liver and renal function tests had been normal, and subsequent tests suggested that the 
Table 1 Reasons for withdrawal

\begin{tabular}{|c|c|c|c|c|}
\hline Disease & $\begin{array}{l}\text { Treatment } \\
\text { period }\end{array}$ & $\begin{array}{l}\text { Age } \\
\text { (years) }\end{array}$ & Sex & Reason \\
\hline \multirow{3}{*}{$\begin{array}{l}\text { Primary Raynaud's } \\
\text { phenomenon }\end{array}$} & Stanozolol & $22 \cdot 4$ & $\mathbf{M}$ & \multirow{2}{*}{$\begin{array}{l}\text { Weight gain, diarrhoea, } \\
\text { myalgia } \\
\text { Malaise } \\
\text { Pregnancy } \\
\text { Weight gain, no benefit } \\
\text { Failure to attend } \\
\text { Weight gain, amenorrhoea } \\
\text { Did not wish to continue }\end{array}$} \\
\hline & & $\begin{array}{l}25 \cdot 2 \\
19 \cdot 9 \\
54 \cdot 3 \\
67 \cdot 8 \\
28 \cdot 0 \\
44.9\end{array}$ & $\begin{array}{l}\mathbf{F} \\
\mathbf{F} \\
\mathbf{F} \\
\mathbf{F} \\
\mathbf{F} \\
\mathbf{F}\end{array}$ & \\
\hline & Placebo & $35 \cdot 8$ & $\mathbf{F}$ & Pregnancy \\
\hline \multirow[t]{5}{*}{ Systemic sclerosis } & Stanozolol & $\begin{array}{l}70 \cdot 5 \\
44 \cdot 4 \\
56 \cdot 7\end{array}$ & $\begin{array}{l}\mathbf{F} \\
\mathbf{F} \\
\mathbf{F}\end{array}$ & \multirow{4}{*}{$\begin{array}{l}\text { Diarrhoea and vomiting } \\
\text { Muscle cramps, moving abroad } \\
\text { Weight gain, muscle cramps, } \\
\text { mouth ulcers } \\
\text { Fluid retention, amenorrhoea, } \\
\text { acne } \\
\text { Weight gain, muscle cramps, } \\
\text { headaches, nausea } \\
\text { Died }\end{array}$} \\
\hline & & $48 \cdot 7$ & $\mathbf{F}$ & \\
\hline & & $49 \cdot 4$ & $\mathbf{F}$ & \\
\hline & & $73 \cdot 7$ & $\mathbf{F}$ & \\
\hline & Placebo & $46 \cdot 5$ & $\mathbf{F}$ & Disease progression \\
\hline
\end{tabular}

deterioration in renal function preceded acute liver failure. She was deeply jaundiced on admission. There was evidence of acute liver cell damage and an enlarged liver with fluid overload and renal failure. Despite dialysis she subsequently developed a large gastrointestinal haemorrhage and died. Permission for a necropsy was refused. This case has been reported to the Committee on Safety of Medicines.

\section{PRIMARY RAYNAUD'S PHENOMENON STUDY Clinical changes}

After 24 weeks' treatment with stanozolol there were non-significant reductions in the frequency $(p=0 \cdot 10)$ and duration $(p=0 \cdot 28)$ of Raynaud's attacks. In contrast, with placebo there were increases in frequency $(p=0 \cdot 16)$ and duration

Table 2 Primary Raynaud's phenomenon study. Euglobulin lysis time and fibrin plate lysis area before and after 1-desamino-8-D-arginine vasopressin stimulation. Values are given as means (SEM)

\begin{tabular}{|c|c|c|c|c|}
\hline & $\begin{array}{l}\text { Week } \\
\text { and } \\
p \text { value }\end{array}$ & Placebo & Stanozolol & $\begin{array}{l}\text { p Value } \\
\text { stanozolol } \\
\mathbf{v} \text { placebo }\end{array}$ \\
\hline \multicolumn{5}{|l|}{ Euglobulin lysis time (min) } \\
\hline Fasting & $\begin{array}{l}0 \\
24 \\
p\end{array}$ & $\begin{array}{c}185.0(36.7) \\
207.5(29.0) \\
0.59\end{array}$ & $\begin{array}{c}225.6(30 \cdot 1) \\
116.1(8 \cdot 0) \\
0.007\end{array}$ & 0.05 \\
\hline After DDAVP* stimulation & $\begin{array}{l}0 \\
24 \\
p\end{array}$ & $\begin{array}{c}54 \cdot 1(10 \cdot 2) \\
77 \cdot 1(7 \cdot 2) \\
0 \cdot 09\end{array}$ & $\begin{array}{c}77 \cdot 2(9 \cdot 7) \\
44.6 \quad(3 \cdot 8) \\
0.02\end{array}$ & 0.02 \\
\hline \multicolumn{5}{|l|}{ Fibrin plate lysis area $\left(\mathrm{mm}^{2}\right)$} \\
\hline Fasting & $\begin{array}{r}0 \\
24\end{array}$ & $\begin{array}{l}146 \cdot 6(17 \cdot 0) \\
107 \cdot 7(13 \cdot 7)\end{array}$ & $\begin{array}{r}93.5(10.6) \\
173.0(12 \cdot 3)\end{array}$ & 0.0009 \\
\hline After DDAVP stimulation & $\begin{array}{l}p_{0} \\
24 \\
p\end{array}$ & $\begin{array}{c}0.02 \\
271 \cdot 0(25 \cdot 1) \\
217 \cdot 9(29 \cdot 7) \\
0.17\end{array}$ & $\begin{array}{c}0.0009 \\
227 \cdot 7(21 \cdot 8) \\
317 \cdot 1(18 \cdot 6) \\
0.05\end{array}$ & $0 \cdot 11$ \\
\hline
\end{tabular}

"DDAVP=1-desamino-8-D-arginine vasopressin.

Table 3 Primary Raynaud's phenomenon study. Changes in fibrinogen and plasminogen with placebo and stanozolol treatment. Values are given as means (SEM)

\begin{tabular}{|c|c|c|c|c|}
\hline & $\begin{array}{l}\text { Week } \\
\text { and } \\
p \text { value }\end{array}$ & Placebo & Stanozolol & $\begin{array}{l}\text { p Value } \\
\text { stanozolol } \\
\text { v placebo }\end{array}$ \\
\hline Fibrinogen $(\mathrm{g} / \mathrm{l})$ & $\begin{array}{l}0 \\
24 \\
p\end{array}$ & $\begin{array}{l}2.66(0.19) \\
3.08(0.37) \\
0.36\end{array}$ & $\begin{array}{l}2 \cdot 74(0.23) \\
2 \cdot 17(0.24) \\
0.04\end{array}$ & 0.06 \\
\hline Plasminogen (\% mean normal) & $\begin{array}{l}0 \\
24 \\
p\end{array}$ & $\begin{array}{c}113.6(6.5) \\
108.3(4.0) \\
0.46\end{array}$ & $\begin{array}{c}106.6(4.8) \\
128.5(6.0) \\
0.003\end{array}$ & 0.03 \\
\hline
\end{tabular}

$(p=0.27)$ of attacks. The differences between the placebo and stanozolol periods were not statistically significant.

\section{Physiological changes}

There were no significant changes in the Doppler index during either 24 week treatment period.

After 24 weeks' treatment with stanozolol there were increases in the mean finger pulp skin temperature $(p=0.18)$ and in the nailbed skin temperature $(p=0 \cdot 16)$. After 24 weeks' treatment with placebo there was a reduction in mean finger pulp finger temperature $(p=0.07)$ and in the mean nailbed skin temperature $(p=0.05)$. The changes of the mean finger pulp and nailbed skin temperatures were not significantly different between the two treatment periods $(p=0.10$ and 0.08$)$ after 24 weeks.

\section{Fibrinolytic changes}

After 24 weeks' stanozolol treatment there were significant reductions in the ELT both in the basal measurements $(p=0.007)$ and after DDAVP stimulation $(p=0.02)$. There were non-significant increases after 24 weeks' treatment with placebo. There were significant differences between the two treatment periods in the basal $(p=0.05)$ and post-DDAVP $(p=0.02)$ measurements of ELT (table 2).

After 24 weeks' stanozolol treatment there were significant increases in the fasting $(p=0.0009)$ and post-DDAVP $(p=0.05)$ measurements of the FPLA. With placebo there was a significant reduction in the fasting FPLA $(p=0.02)$ and a non-significant reduction $(p=0.17)$ after DDAVP. The differences in fasting FPLA between the two treatment periods were significantly different $(p=0.0009)$ (table 2).

There was a significant reduction in plasma fibrinogen $(p=0.04)$ after 24 weeks of treatment with stanozolol and a non-significant increase after 24 weeks with placebo. The differences between treatments were not significantly different $(p=0.06)$ (table 3$)$.

There was a significant increase in plasminogen $(p=0.003)$ with stanozolol treatment but no significant change with placebo. The differences between the two treatments were significantly different $(p=0.03)$ (table 3$)$.

No significant changes were found in the $\alpha_{2}$ antiplasmin or $\alpha_{2}$ macroglobulin concentrations.

\section{SYSTEMIC SCLEROSIS STUDY}

\section{Clinical changes}

There were reductions in the mean frequency of Raynaud's attacks during both stanozolol $(p=0.45)$ and placebo $(p=0.44)$ treatment. These changes did not reach statistical significance, and there were no significant differences between the two treatment periods $(p=0.94)$. The duration of individual attacks fell after 24 weeks' treatment with stanozolol $(p=0: 38)$ and increased after placebo $(p=0 \cdot 63)$. These changes were not significant and there were no 
significant differences between the two treatment periods $(p=0.44)$.

The scleroderma skin score remained unchanged during placebo treatment and fell with stanozolol, but the changes were not significant (fig 1).

Mean grip strength (fig 2) increased after treatment with stanozolol $(p=0 \cdot 14)$ and decreased with placebo $(p=0 \cdot 15)$. These changes and the differences between them were not significant $(p=0.07)$.

\section{Physiological changes}

There was a significant increase in the ultrasonic Doppler index (fig 3) after 24 weeks' treatment with stanozolol $(p=0.006)$ and a significant decrease with placebo $(p=0.02)$. The difference between the two treatment periods was significant $(p=0.007)$.

During stanozolol treatment there were significant increases in finger pulp $(p=0.001)$ and nailbed $(p=0.001)$ temperatures, whereas after placebo there was a non-significant decrease in finger pulp ( $p=0.08)$ and a significant decrease in nailbed $(p=0.04)$ temperatures. The differences between stanozolol and placebo periods

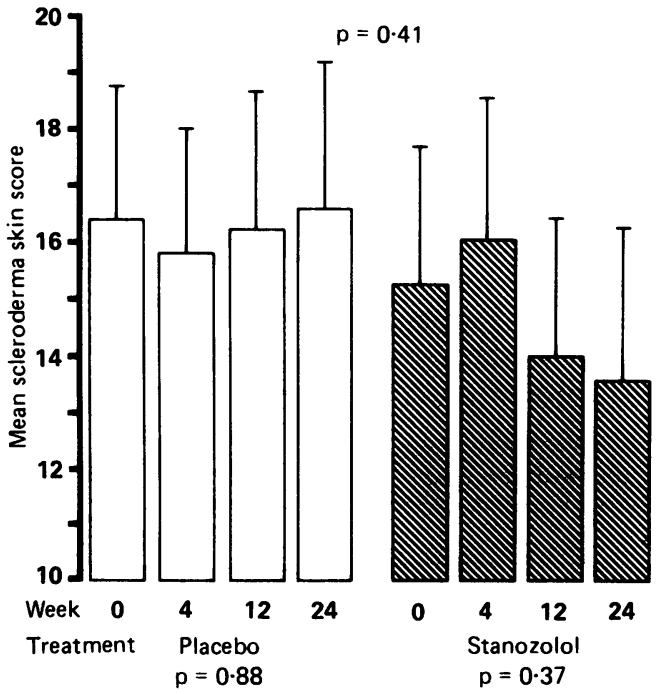

Figure 1 Systemic sclerosis. Mean scleroderma skin score (SEM) during placebo and stanozolol treatment.

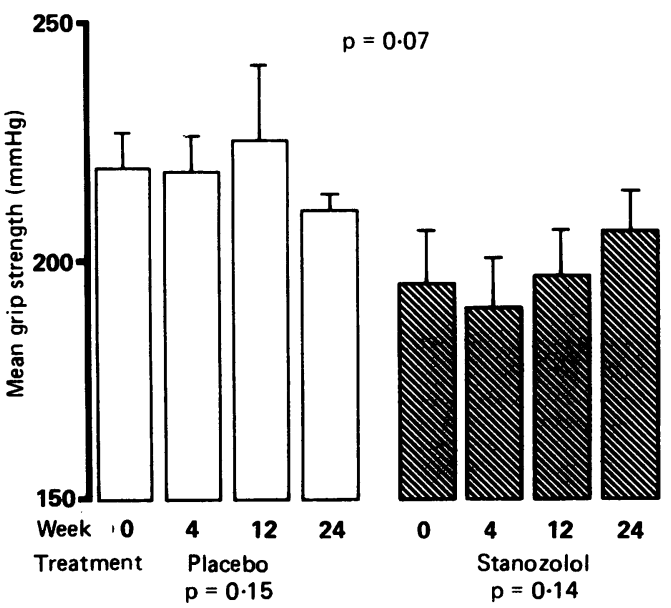

Figure 2 Systemic sclerosis. Mean grip strength (SEM) during placebo and stanozolol treatment.

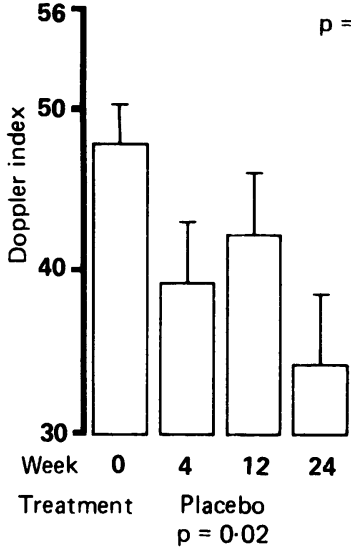

$p=0.007$

Figure 3 Systemic sclerosis. Mean ultrasonic Doppler index (SEM) during placebo and stanozolol treatment.

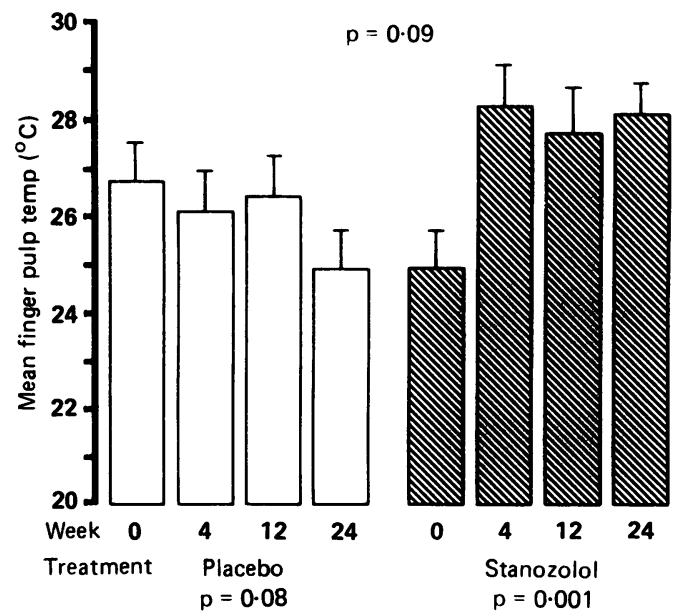

Figure 4 Systemic sclerosis. Mean finger pulp temperature (SEM) during placebo and stanozolol treatment.

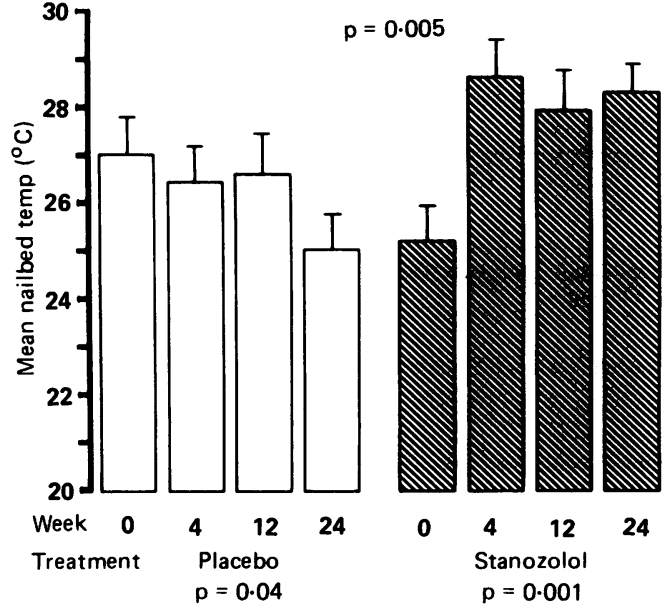

Figure 5 Systemic sclerosis. Mean nailbed temperatures (SEM) during placebo and stanozolol treatment.

were significant for nailbed $(p=0.005)$ but not finger pulp temperatures $(p=0 \cdot 09)$ (figs 4 and 5).

\section{Fibrinolytic changes}

There was a significant reduction in the fasting ELT $(p=0.05)$ and non-significant reduction after DDAVP stimulation $(p=0.09)$ with 
Table 4 Systemic sclerosis study. Euglobulin lysis time and fibrin plate lysis area before and after 1-desamino-8-D-arginine vasopressin (DDAVP) stimulation. Values are given as means (SEM)

\begin{tabular}{|c|c|c|c|c|}
\hline & $\begin{array}{l}\text { Week } \\
\text { and } \\
\text { p value }\end{array}$ & Placebo & Stanozolol & $\begin{array}{l}\text { p Value } \\
\text { stanozolol } \\
\text { v placebo }\end{array}$ \\
\hline \multicolumn{5}{|l|}{ Euglobulin lysis time (min) } \\
\hline Fasting & $\begin{array}{l}0 \\
24 \\
p\end{array}$ & $\begin{array}{c}226.9(43.0) \\
204.1(23.6) \\
0.58\end{array}$ & $\begin{array}{c}243 \cdot 6(31 \cdot 4) \\
156 \cdot 3(24 \cdot 7) \\
0.05\end{array}$ & 0.33 \\
\hline After DDAVP stimulation & $\begin{array}{l}0 \\
24 \\
p\end{array}$ & $\begin{array}{c}98 \cdot 6(23 \cdot 3) \\
75 \cdot 3(11 \cdot 8) \\
0.50\end{array}$ & $\begin{array}{c}97.4(14 \cdot 1) \\
60.9(8.9) \\
0.09\end{array}$ & 0.83 \\
\hline \multicolumn{5}{|l|}{ Fibrin plate lysis area $\left(\mathrm{mm}^{2}\right)$} \\
\hline Fasting & $\begin{array}{l}0 \\
24 \\
p\end{array}$ & $\begin{array}{c}123 \cdot 2(14 \cdot 4) \\
104 \cdot 7(10 \cdot 8) \\
0 \cdot 24\end{array}$ & $\begin{array}{c}106 \cdot 7(12 \cdot 1) \\
143 \cdot 7(15 \cdot 3) \\
0.05\end{array}$ & 0.08 \\
\hline After DDAVP stimulation & $\begin{array}{l}0 \\
24 \\
p\end{array}$ & $\begin{array}{c}230.7(20.6) \\
232.8(25 \cdot 7) \\
0.79\end{array}$ & $\begin{array}{c}228.6(21 \cdot 4) \\
255.9(27 \cdot 2) \\
0.49\end{array}$ & 0.92 \\
\hline
\end{tabular}

Table 5 Systemic sclerosis study. Changes in fibrinogen and plasminogen with placebo and stanozolol treatment. Values are given as means (SEM)

\begin{tabular}{|c|c|c|c|c|}
\hline & $\begin{array}{l}\text { Week } \\
\text { and } \\
p \text { value }\end{array}$ & Placebo & Stanozolol & $\begin{array}{l}\text { p Value } \\
\text { stanozolol } \\
\mathrm{v} \text { placebo }\end{array}$ \\
\hline Fibrinogen $(\mathrm{g} / \mathrm{l})$ & $\begin{array}{l}0 \\
24 \\
p\end{array}$ & $\begin{array}{l}2.86(0.29) \\
3.01(0.20) \\
0.56\end{array}$ & $\begin{array}{c}3.02(0.21) \\
2.46(0.25) \\
0.07\end{array}$ & $0 \cdot 17$ \\
\hline Plasminogen (\% mean normal) & $\begin{array}{l}0 \\
24 \\
p\end{array}$ & $\begin{array}{c}118 \cdot 8 \quad(5 \cdot 8) \\
109 \cdot 1(4 \cdot 8) \\
0 \cdot 17\end{array}$ & $\begin{array}{c}104.9(4 \cdot 0) \\
128 \cdot 2(4 \cdot 0) \\
0.002\end{array}$ & 0.002 \\
\hline
\end{tabular}

stanozolol treatment, but these did not reach statistical significance when compared with the placebo data. Similarly, there was a significant increase in the fasting FPLA $(p=0.05)$ and nonsignificant increase after DDAVP $(p=0.49)$ with stanozolol (table 4). There was a nonsignificant fall in fibrinogen during stanozolol treatment and an increase with placebo. There was a significant increase in plasminogen after 24 weeks' treatment with stanozolol $(p=0.002)$ compared with a non-significant decrease with placebo. The two treatment periods were significantly different $(p=0.002)$ (table 5). There were no significant changes in the $\alpha_{2}$ antiplasmin and $\alpha_{2}$ macroglobulin concentrations.

\section{Discussion}

Raynaud's phenomenon is a common problem. In primary Raynaud's phenomenon no underlying cause can be found on clinical examination or investigation. During long term follow up no underlying disorder is detected in most of these patients. In a small proportion, however, evidence of an underlying connective tissue disorder may become apparent.

The mechanisms underlying primary Raynaud's phenomenon are uncertain. In particular there may be abnormal vascular reactivity with vasoconstriction occurring on exposure to cold. Hyperviscosity of the blood has been described. ${ }^{1}$ In that study, however, in choosing their patients with Raynaud's phenomenon the authors apparently did not exclude patients showing immunological evidence of connective tissue disease, and possibly their results are due to the inclusion of such subjects. Studies of plasma fibrinogen and of the fibrinolytic system have not shown any abnormality in patients with carefully characterised primary Raynaud's phenomenon and there is no evidence that fibrinolytic abnormalities play any part in the pathogenesis of this disorder. $^{3}$

In contrast, in systemic sclerosis there is progressive vascular obliteration, with intimal proliferation associated with platelet aggregation to the vessel walls and endothelial damage. Fibrin deposition in the vessel walls may contribute towards vascular obstruction. ${ }^{7}$ Progressive narrowing of the peripheral arterioles leads to a decrease in digital artery pressure and digital blood flow. In particular, the critical closing pressure of the digital blood vessels may decrease so that peripheral blood flow becomes more sensitive to other factors, such as cold. There is an increase of blood viscosity. ${ }^{2}$ This is associated with hyperfibrinogenaemia and diminished fibrinolytic activity. In addition, fibrin may be deposited in the perivascular tissues and block diffusion of oxygen. As a result of vascular insufficiency patients with systemic sclerosis commonly have severe Raynaud's phenomenon frequently complicated by digital pitting and ulceration.

Defective fibrinolytic activity is common in systemic sclerosis ${ }^{3}$ and may contribute towards the hyperfibrinogenaemia and the persistence of fibrin deposits in vessel walls and perivascular tissues. For this reason stimulation of the fibrinolytic system and correction of the defect may be of therapeutic value in improving the vascular problems. The relation between vascular changes and connective tissue proliferation in systemic sclerosis remains uncertain. There is evidence that microvascular injury occurs first. ${ }^{8}$ If this is so, correction of the vascular problem might help to control the proliferation of collagen and other connective tissue elements in systemic sclerosis.

Stanozolol is an anabolic steroid with relatively little androgenic activity. It has been shown to 
enhance impaired fibrinolytic activity. ${ }^{9}$ In lipodermatosclerosis there is chronic induration and fibrosis of the skin and subcutaneous tissues of the leg after deep venous thrombosis. Fibrin is deposited in the tissues and there is a fibrinolytic defect in the blood. Fibrinolytic enhancement with stanozolol is effective in correcting the defect, reducing the fibrin in the tissues and reducing the area of liposclerosis. ${ }^{10}$ Clinical improvements by similar mechanisms are suggested in rheumatoid arthritis ${ }^{11}$ and in cutaneous vasculitis. ${ }^{12}$

A previous study of systemic sclerosis and Raynaud's phenomenon suggested stanozolol is of value. ${ }^{4}$ This was an uncontrolled study, however in which patients received stanozolol for two periods of three months with an intervening period of three months without drug treatment. Raynaud's phenomenon and systemic sclerosis are extremely difficult to assess and placebo controlled studies are essential to evaluate any form of treatment. Moreover, although the authors state the trial was in patients with both idiopathic and scleroderma associated Raynaud's phenomenon, they did not define the criteria for either group. All these 20 patients in the trial had severe bilateral disease with trophic changes and symptoms such as pain and recurrent infection in the finger tips. From review of the paper it seems likely that they all had systemic connective tissue disease. We have conducted, therefore, further and more detailed studies to determine the clinical, physiological, and biochemical effects of stanozolol in patients with primary Raynaud's phenomenon and systemic sclerosis.

Assessment of Raynaud's phenomenon is notoriously difficult. In particular, in long term studies subjective assessments of frequency and severity of Raynaud's attacks are complicated by change in season and it can be very difficult to determine the values of any form of treatment without objective measures of peripheral blood flow after stabilisation at controlled temperatures. Patients have more and longer attacks in the winter than in the summer and it is possible that winter weather plus an effective agent equates with summer weather plus placebo so that a real effect might be missed. For these reasons we attach much greater value to the objective measurements than to the subjective recordings of frequency and duration of Raynaud's attacks.

In patients with primary Raynaud's phenomenon there were some small non-significant trends towards improvement in the peripheral microcirculation during the stanozolol treatment periods compared with the control treatment periods. It remains possible that some of these patients with primary Raynaud's phenomenon were in the early stages of connective tissue disease but without any clinical features. Benefit in these subjects might account for the minor improvements that were seen. In view of the side effects there is no indication for stanozolol in primary Raynaud's phenomenon.

In the patients with systemic sclerosis the duration of Raynaud's attacks fell during stanozolol treatment and increased with placebo, though these differences were not significant.
The objective measures of peripheral blood flow, however, showed significant improvements during stanozolol treatment compared with placebo. These differences were marked in terms of digital patency measured by the ultrasonic Doppler index and skin temperatures both of the finger pulps and nail beds. These results indicate a marked improvement in the microcirculation during the period of stanozolol treatment.

Anecdotal evidence suggests that fibrinolytic enhancement is most effective if given early in the disease. Once vessels are totally occluded, and perhaps fibrin deposits are stabilised and the patient is showing major evidence of peripheral ischaemia possibly with digital gangrene, only limited improvement, if any, may be expected during treatment with stanozolol. A further trial of fibrinolytic enhancement specifically limited to early systemic sclerosis is indicated.

We also found a non-significant improvement in the scleroderma skin score, which is an index of the degree of skin affected by fibrotic change. The number of patients in this study was small. It remains possible that a larger study of longer duration might show significant improvement of skin involvement during treatment with stanozolol.

The grip strength increased during stanozolol treatment and decreased during the control periods. If this is a real change it may reflect the control of the underlying disease. Differences in grip strength may be due to the anabolic effects of stanozolol on muscle strength, however.

Defective fibrinolytic activity is well recognised in systemic sclerosis but not in carefully defined primary Raynaud's phenomenon. ${ }^{3}$ In this study we found a prolonged ELT and reduced FPLA in the patients with systemic sclerosis compared with those with primary Raynaud's phenomenon. Stanozolol is known to stimulate fibrinolytic activity, ${ }^{9}$ and in the current studies we found that the treatment period was associated with a fall in the ELT, an increase in the FPLA, and a reduction in plasma fibrinogen concentrations. Fibrinolytic activity is determined by the concentrations of tissue plasminogen activator, which is derived from the vascular endothelium. ${ }^{13}$ This forms the active fibrin adsorbable component of tissue plasminogen activator, ${ }^{14}$ and the plasminogen activator activity seems to be a balance between the amounts of activator and inhibitor that are present. Stanozolol appears to act, at least in part, by decreasing the concentrations of tissue plasminogen activator inhibitor. ${ }^{15}$ Perhaps demonstration of raised concentrations of tissue plasminogen activator inhibitor may indicate those patients most likely to respond to treatment with stanozolol.

Venous occlusion leads to enhancement of fibrinolytic activity and is thought to be due to release of tissue plasminogen activator from the vessel walls. ${ }^{16}$ This has been termed the fibrinolytic reserve. The standard test requires venous occlusion for 20 minutes and presents special difficulties in patients with peripheral vascular impairment as in systemic sclerosis. 1-Desamino8-D-arginine vasopressin (DDAVP) given by 
infusion produces a profound increase in fibrinolytic activity. Infusion of $10 \mu \mathrm{g}$ DDAVP led to a marked increase in fibrinolytic activity in healthy subjects, ${ }^{17}$ and it has been possible to show a fivefold to sevenfold increase in fibrinolytic activity with infusions of $0.4 \mu \mathrm{g}$ of DDAVP per kg body weight. ${ }^{18}$

We found a significant reduction in response to DDAVP in patients with systemic sclerosis compared with controls, ${ }^{19}$ suggesting defective reserve or release of endothelial cell derived plasminogen activator in systemic sclerosis. In the patients with systemic sclerosis we found no obvious differences in the responses DDAVP during stanozolol and placebo treatment periods, though in the patients with primary Raynaud's phenomenon there might have been a greater response to DDAVP in those receiving stanozolol rather than placebo. This again suggests that in systemic sclerosis stanozolol does not affect vessel wall plasminogen activator storage or release. It is compatible with the proposal that stanozolol principally stimulates the fibrinolytic system by inhibiting formation of tissue plasminogen activator inhibitor.

Considerably more adverse events were recorded by a questionnaire during both treatment and placebo periods than before the trial. They were somewhat more common during stanozolol treatment than with placebo, but there were no clear differences in patterns of adverse events.

Withdrawals from the trial occurred predominantly during treatment with stanozolol and were usually due to anabolic effects. One patient died during stanozolol treatment with acute hepatorenal failure. She had rapidly advancing systemic sclerosis with visceral manifestations. Acute renal failure is a common problem in this subclass of systemic sclerosis and is the commonest cause of death. She did develop acute hepatocellular damage, however, though the sequence of liver function tests suggests that this followed the deterioration of renal function. It is known that stanozolol may raise the levels of liver enzymes such as aspartate transaminase and alanine transaminase. ${ }^{10}$ It remains uncertain whether the acute hepatocellular damage in this case was an adverse effect of stanozolol.

In conclusion, controlled studies of stanozolol have been performed in primary Raynaud's phenomenon and systemic sclerosis. In primary Raynaud's phenomenon there was a minimal suggestion of clinical improvement but a high proportion of withdrawals, principally because of anabolic effects in a young female population.
There does not seem to be any indication for the use of stanozolol in primary Raynaud's phenomenon. In systemic sclerosis there was a significant and marked improvement in the peripheral microcirculation by objective but not subjective measures, and a non-significant improvement in the scleroderma skin score. Adverse effects again were common. Stanozolol does seem to be useful in treating the microvascular features of systemic sclerosis.

We wish to thank Sterling Research Laboratories for supporting this study.

1 Goyle K B, Dormandy F L. Abnormal blood viscosity in Raynaud's phenomenon. Lancet 1976; i: 1317-8.

2 McGrath M A, Peek R, Penny R. Blood viscosity with reduced blood flow in scleroderma. Ann Rheum Dis 1977; 26: $569-74$.

3 Holland C D, Jayson M I V. Venous blood fibrinolysis and fibrinolytic potential in primary Raynaud's phenomenon and systemic sclerosis associated Raynaud's phenomenon. In: Black C M, Myers A R, eds. Progressive systemic In: Black C M, Myers A R, eds. Progressit
sclerosis. New York: Gower, 1985: 267-73.

4 Jarrett P E M, Morland M, Browse N L. Treatment of Raynaud's phenomenon by fibrinolytic enhancement. $\mathrm{Br}$ Med F 1978; ii: 523-5

5 Masi A T, Rodnan G P, Medsger T A, et al. Preliminary criteria for classification of systemic sclerosis (scleroderma). Arthritis Rheum 1980; 23: 581-90.

6 Hills M, Armitage P. The two-period cross-over clinical trial. Br F Clin Pharmacol 1979; 8: 7-20.

7 Norton $W$ L. Comparison of the microangiopathy of systemic lupus erythematosus, dermatomyositis, scleroderma and diabetes mellitus. Lab Invest 1970; 22: 301-8.

8 Freemont A J, Hodson N, Mitchell W, Jayson M I V. Microvascular injury precedes fibrosis in systemic sclerosis. Br F Rheumatol 1987; 26 (suppl 2): 42.

9 Preston F E, Burakowski B K, Porter N R, Malia R G. The fibrinolytic response to stanozolol in normal subjects. Thromb Res 1981; 22: 543-51.

10 Browse N L, Jarrett P E M, Morland M, Burnand K. Treatment of liposclerosis of the leg by fibrinolytic enhancement. Br Med F 1977; ii: 434-5.

11 Belch J J F, Madhok R, McArdle B, et al. The effect of increasing fibrinolysis in patients with rheumatoid arthritis: a double blind study of stanozolol. $Q \mathcal{F}$ Med 1986; 225: $19-27$.

12 Cunliffe W J, Dodman B, Roberts B E, Tebbs E M. Clinical and laboratory double-blind investigation of fibrinolytic therapy of cutaneous vasculitis. In: Davidson J F, Samama M M, Desnoyers P C, eds. Progress in chemical fibrinolysis and thrombolysis. Vol. 1. New York: Raven Press, 1975: 325-32.

13 Rijken D C, Wijngaard S, Welbergen J. Relationship between tissue plasminogen activator and the activators in
blood and vascular wall. Thromb Res 1980; 18: 815-30.

14 Rijken D C, Juhan-Vague I, De Koch F, Collen D. Measurement of human tissue-type plasminogen activator by a two-site immunoradiometric assay. $\mathcal{F}$ Lab Clin Med 1983; 101: 274-84.

15 Verheijen J H, Rijken D C, Chang G T G, Preston F E, Kluft C. Modulation of rapid plasminogen activator inhibitor in plasma by stanozolol. Thromb Haemost 1984; 51: 396-7.

16 Robertson D R, Pandolfi M, Nilsson I M. "Fibrinolytic capacity" in healthy volunteers as estimated from effects of venous occlusion of arms. Acta Chir Scand 1972; 138: 429-36.

17 Gader A M A, Da Costa J, Cash J D. A new vasopressin analogue and fibrinolysis. Lancet 1973; ii: 1417-8.

18 Manucci P M, Rota L. Plasminogen activator response after DDAVP: a clinico-pharmacological study. Thromb Res 1980; 20: 69-76.

19 Holland C D, Keegan A L, Wood K, Jayson M I V. The fibrinolytic response to DDAVP in systemic sclerosis and controls. In: Davidson J F, Bachmann F, Bouvier C A, Kruithof E K O, eds. Progress in fibrinolysis. Vol VI. Edinburgh: Churchill Livingstone, 1983: 107-10. 